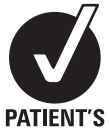

CHOICE

\title{
Impact of STN-DBS on life and health satisfaction in patients with Parkinson's disease
}

\author{
Joseph Ferrara, Alan Diamond, Christine Hunter, Anthony Davidson, \\ Michael Almaguer, Joseph Jankovic
}

Parkinson Disease Center and Movement Disorders Clinic, Department of Neurology, Baylor College of Medicine, Houston, Texas, USA

\section{Correspondence to}

Dr Joseph Jankovic, Parkinson Disease Center and Movement Disorders Clinic, Department of Neurology, Baylor College of Medicine, 6550 Fannin, Suite 1801, Houston, TX 77030, USA; josephj@bcm.tmc.edu

Received 26 May 2009

Revised 9 July 2009

Accepted 18 July 2009

\section{ABSTRACT \\ Objective Advanced Parkinson's disease (PD) is associated with various motor and non-motor symptoms which adversely impact health-related quality of life (HROoL). Subthalamic nucleus (STN) deep brain stimulation (DBS) has been reported to improve some dimensions of HROoL in appropriately selected candidates. Prior studies of HROoL following DBS have used instruments comprising a predetermined list of questions which assess issues that are generally relevant in PD, but that may not be of equal or consistent importance to all individuals. In this study, we evaluate the effect of STN DBS on quality of life using the OLS ${ }^{\mathrm{M}}$, a modular questionnaire in which satisfaction scores for each item are weighted in light of patient-rated importance.}

Methods We prospectively analysed $\mathrm{OLS}^{\mathrm{M}}$ scores in 21 patients with PD (11 men, mean age $61.5 \pm 8.6$ years) before STN DBS surgery and at a mean 7.4 \pm 1.5 , and again at a mean $16.6 \pm 6.8$ months postoperatively.

Results Following STN DBS, patients experienced an improvement in HROoL as measured by various items of the movement disorder and health modules of the OLS ${ }^{\mathrm{M}}$. Specifically, OLS ${ }^{\mathrm{M}}$ items pertaining to energy level/ enjoyment of life, independence from help, controllability/ fluidity of movement and steadiness when standing and walking showed significant improvements, although items concerning general life issues (eg, occupational function, interpersonal relationships, leisure activities) did not improve.

Conclusion Following STN DBS, symptomatic and functional improvements translate into higher $\mathrm{HROOL}$, with high satisfaction in domains related to movement disorders and general health.

\section{INTRODUCTION}

Parkinson's disease (PD) is a progressive neurodegenerative disorder characterised by motor, sensory, autonomic, cognitive-behavioural and sleep-related symptoms. Dopaminergic medications, the cornerstone of PD treatment, alleviate a subset of these symptoms, but drug efficacy may wane over time. Furthermore, dopamine replacement therapy, especially levodopa, often produces complications which have a negative impact on patient function, including motor fluctuations and dyskinesias. In a subset of PD patients with levodopa-induced motor complications, high-frequency DBS is uniquely suited to improve both PD motor deficits as well as medication-related complications, and the efficacy of DBS in this setting is now well established. ${ }^{1}$ STN DBS, however, fails to address numerous symptoms that are disabling in advanced
$\mathrm{PD}$, such as levodopa-refractory axial motor disturbances. Also, DBS is itself associated with potential side effects including postoperative complications, ${ }^{2} 3$ cognitive dysfunction, ${ }^{4-7}$ depression, ${ }^{8}$ social maladjustment ${ }^{9}$ and impaired articulation ${ }^{10}$-all of which may impact patient satisfaction. ${ }^{11-15}$

Given these complexities, clinicians have increasingly utilised patient-based outcome measures, such as health status (HS) and healthrelated quality of life (HRQoL), to characterise and quantify the benefits of PD treatments. There is not yet a universally accepted definition of either HS or HRQoL, but there is growing opinion that, though inter-related, $\mathrm{HS}$ and HRQoL are distinct constructs. HS refers to an individual's assessment of his/her physical, mental and social condition and function. ${ }^{11} 16$ The WHO defines quality of life as 'an individual's perception of his/her position in life in the context of the culture and value systems in which he/she lives and in relation to his/her goals, expectations, standards and concerns. ${ }^{17} \mathrm{HRQoL}$ is conceptually similar to quality of life but targeted to matters of medical well-being. Accordingly, HS questionnaires focus on the presence of symptoms (eg, motor dysfunction, fatigue, pain, embarrassment or loneliness) and their impact on one's ability to perform various life activities (eg, housework, bathing, communicating or leisure activities), while HRQoL instruments measure a patient's subjective experience of symptoms and satisfaction with health conditions. HRQoL differs from HS in that it gauges not only the presence and severity of functional limitations, but also to what extent such restrictions actually disturb the individual. ${ }^{11} 16$ The distinction between HS and HRQoL is of consequence because differences in lifestyle, social support, coping mechanisms and personality traits may influence how HS variables affect HROoL, ${ }^{18} 19$ and available data indicate that patients themselves view HS and HRQoL as distinct constructs. ${ }^{11} 131620$ The division is not meant to invalidate the utility of HS instruments, rather to emphasise that a modest problem in an area of great personal importance may impact an individual's quality of life more so than a severe problem that is of lesser personal importance.

Several prior studies have demonstrated improvements in HS following DBS, ${ }^{1121} 22$ yet all have employed questionnaires (such as the PDQ-39 and PDOL) that evaluate $\mathrm{HS}$ in $\mathrm{PD}$, thus providing only an approximation of HRQoL. Furthermore, studies have arrived at conflicting results regarding the effect of DBS on certain HS parameters, ${ }^{22}$ such as communication. ${ }^{19}{ }^{23-26}$ Most studies have 
shown that cognitive and social HS remains static following DBS, ${ }^{23}{ }^{27-30}$ but results in these domains are also mixed. ${ }^{31-33}$ Accordingly, we sought to provide pilot data regarding outcome following STN DBS using the Questions on Life Satisfaction $\left(\mathrm{OLS}^{\mathrm{M}}\right)$ modular questionnaire, a recently validated movement disorder and DBS-specific HRQoL instrument in which satisfaction scores for each item are weighted in light of patient-rated importance. $^{34}$

\section{METHODS \\ Participants}

We enrolled 23 consecutive patients with PD, defined according to the UK Parkinson's Disease Brain Bank criteria, ${ }^{35}$ who underwent DBS at the Baylor College of Medicine Movement Disorders Clinic in Houston, Texas. All had an excellent response to levodopa but developed motor complications refractory to medical management and met inclusion criteria for STN DBS, as per the recommendations of the CAPSIT-PD panel. ${ }^{36}$ Exclusion criteria were as follows: age $<30$ or $>75$ years, Mini-Mental Status Examination (MMSE) score $<24$ or other evidence of dementia on a comprehensive neuropsychological evaluation, medically uncontrolled psychiatric comorbidity and medical contraindications to surgery. The final decision for implantation was made in a multidisciplinary meeting attended by a neurosurgeon, movement disorder specialists, clinical nurses and a neuropsychologist. One hundred per cent of eligible patients consented to participate in the study, but two were lost to follow-up after their baseline (preoperative) assessment due to geographical limitations and were not included in our analysis. An additional two patients completed their first but not second follow-up assessment. All patients signed an informed consent before entering the study, and the study protocol was approved by the Baylor College of Medicine Internal Review Board for Human Research.

\section{Surgical procedure}

All STN DBS procedures were performed by one neurosurgeon in two stages: (1) insertion of bilateral electrodes (Medtronic 3389, Minneapolis, Minnesota) under local anaesthesia, and (2) connection of the electrodes to pulse generators under general anaesthesia, performed approximately 1 week after lead placement. For electrode implantation, stereotactic guidance, microelectrode recording and macroelectrode stimulation with neurological monitoring were used to determine the optimal site for placement. During the follow-up period, medication and DBS parameters were individually optimised in repeated programming sessions.

\section{Evaluation procedures}

HRQoL was prospectively measured via an expanded version of the Questions on Life Satisfaction $\left(\mathrm{OLS} \mathrm{S}^{\mathrm{M}}\right.$ ), a modular questionnaire that has been designed specifically to evaluate quality of life in the DBS population. ${ }^{34}$ The OLS $^{M}$ contains modules which address general life satisfaction $\left(\mathrm{OLS}^{\mathrm{M}}-\mathrm{A}\right)$, general health satisfaction (OLS $\left.{ }^{\mathrm{M}}-\mathrm{G}\right)$, movement disorder-specific health satisfaction $\left(\mathrm{OLS}^{\mathrm{M}}-\mathrm{MD}\right)$ and satisfaction with DBS (OLS $\left.{ }^{\mathrm{M}}-\mathrm{DBS}\right)$. The OLS ${ }^{M}-M D$ comprises 12 items, the $\mathrm{OLS}^{\mathrm{M}}$-DBS comprises five items, and the OLS ${ }^{\mathrm{M}}-\mathrm{A}$ and $\mathrm{OLS}^{\mathrm{M}}{ }_{-} \mathrm{G}$ each have eight. OLS ${ }^{\mathrm{M}}$ $\mathrm{MD}$ includes questions concerning fluidity of movement, balance, hand dexterity, speech, swallowing, sensory phenomena, bladder and intestinal function, sexual function, sleep, memory and clarity of thinking, independence from help, and conspicuousness of illness. OLS ${ }^{\mathrm{M}}$-DBS includes questions concerning reliability, visibility, independent handling, physician care and side effects of the neurostimulator. Questions on the $\mathrm{OLS}^{\mathrm{M}}$-A concern friendships, leisure activities, overall health, financial security, occupational function, living conditions, family life and partner (spousal) relationships. The OLS ${ }_{-}^{\mathrm{M}} \mathrm{G}$ comprises questions regarding physical condition, relaxation and inner peace, energy level, discomfort and pain, mobility, hearing and vision, anxiety and independence. Each $\mathrm{OLS}^{\mathrm{M}}$ module is divided into two sections: one section rates the importance of various items and the other, the satisfaction associated with each item. Importance and satisfaction scores for each item are combined to provide information about weighted satisfaction; accordingly, scores reflect one's satisfaction with items that one considers to be important. Weighted satisfaction scores may range between -12 and +20 for each item, with higher scores indicating an increase in quality of life. Weighted satisfaction is calculated by the following formula: weighted satisfaction= (importance rating -1$) \times[(2 \times$ satisfaction rating $)-5]$. Patient scores reflect HRQoL over the preceding 4 weeks. Floor and ceiling effects of the scale are negligible. Content validity of the OLSM was obtained through exploratory interviews with patients. Construct validity was established by means of correlations with established instruments: Medical Outcomes Study 36-Item Short-Form Health Survey (SF-36) and the EuroOol (EQ5D). ${ }^{3738}$ The Cronbach $\alpha$ values of the module summary-scores are as follows: 0.70 for the OLSM-A, 0.75 for the OLSM-G, 0.87 for the OLSM-MD and 0.73 for the OLSM-DBS. ${ }^{34} 39$

Supplemental assessments included the Geriatric Depression Scale (GDS), ${ }^{40}$ Unified Parkinson's Disease Rating Scale (UPDRS) ${ }^{41}$ Lang-Fahn activities of daily living dyskinesia scale (LFADLDS), ${ }^{42}$ Modified Hoehn and Yahr score, ${ }^{43}$ Folstein Minimental status examination ${ }^{44}$ and EQ-5D. ${ }^{37}$ The EQ-5D is a standardised instrument for valuing $\mathrm{HS}$ across five domains (mobility, self-care, usual activity, pain/discomfort and anxiety/ depression). Data were collected and scored as per the published guidelines for each instrument.

Prospective clinical assessments were performed at baseline (within 30 days prior to surgery), and at approximately 6 $(7.4 \pm 1.5)$ and $12(16.6 \pm 6.8)$ months postoperatively. All three assessments were identical, with two exceptions. First, prior to DBS, the UPDRS was performed in the medically 'off' and 'on' states. The medical 'off' state was achieved by having patients hold anti-PD medications for $>12 \mathrm{~h}$ prior to their examination; subsequently the medical 'on' state was achieved by having patients take 1-1.5 times their usual morning levodopa dose, followed by an examination 1-2 h later. After DBS surgery, the UPDRS was assessed off dopaminergic medications following optimisation of stimulation parameters. Second, the OLS ${ }^{\mathrm{M}}$-DBS satisfaction scores could not be assessed preoperatively, but the importance subsection of the OLS $^{\mathrm{M}}$-DBS was completed at baseline. Adverse events were prospectively recorded at each clinic visit.

\section{Data analysis}

The primary outcome measure was the change from baseline in the $\mathrm{OLS}^{\mathrm{M}}-\mathrm{MD}$ summary weighted score following DBS. Secondary outcome measures included change from baseline in other OLS $^{\mathrm{M}}$ modules, UPDRS, LFADLDS and the additional instruments cited above. Change from baseline was analysed by repeated-measures analysis of variance (ANOVA). Huynh-Feldt epsilon correction was used to compensate for lack of independence. The Pearson product-moment correlation $(\rho)$ was used to identify associations between HRQoL (change in OLSM-MD summary score from assessment 1 to 3 ) and clinical variables. The criterion for statistical significance was set at a two-sided 
$\mathrm{p}$ of $\leq 0.05$. All analyses were preformed using Stata IC version 10.1 for Windows.

\section{RESULTS}

Sociodemographic and baseline clinical characteristics are listed in tables 1,2. STN DBS produced significant improvements in LFADLDS and UPDRS part II, III and IV scores as well as general health $\left(\mathrm{OLS}^{\mathrm{M}}-\mathrm{G}\right)$ and movement disorder health $\left(\mathrm{OLS}^{\mathrm{M}}{ }^{-\mathrm{MD}}\right)$ satisfaction (table 2). The following HROoL domains significantly improved following surgery: OLS ${ }^{\mathrm{M}}-\mathrm{G}$ items pertaining to energy level/enjoyment of life and independence from help; and $\mathrm{OLS}^{\mathrm{M}}$-MD items pertaining to controllability/fluidity of movement, steadiness when standing and walking, hand dexterity (eg, when eating and writing), absence of false bodily sensations, undisturbed sleep, independence from help and inconspicuousness of illness. OLS ${ }^{\mathrm{M}}$-MD items concerning swallowing, bladder/ intestinal function and cognition insignificantly improved following surgery, while items related to articulation and sexual excitability insignificantly worsened. No items on the general life satisfaction module (OLS ${ }^{\mathrm{M}}$-A) changed significantly following surgery. On the OLS ${ }^{\mathrm{M}}$-DBS, patients rated neurostimulator reliability, doctoral care and the absence of bodily symptoms as more important than inconspicuousness or independent handling of the stimulator. Weighted scores on the DBS module of the OLS ${ }^{\mathrm{M}}$ showed high satisfaction (table 2), which remained stable between the two postoperative assessments (Student $t$ test, $\mathrm{p}=0.45)$.

The difference in preoperative Hoehn and Yahr scores between the medically 'off' and 'on' states correlated with improvement in the $\mathrm{OLS}^{\mathrm{M}}$-MD summary score $(\mathrm{r}=0.72, \mathrm{p}=0.0005)$. No other baseline variable predicted long-term improvement in HRQoL. We also assessed the relationship between $\mathrm{HRQoL}$ and changes in clinical parameters following surgery. HRQoL benefits correlated with the postoperative improvements in the off-state UPDRS part II $(\mathrm{r}=-0.59, \mathrm{p}=0.046)$ and the GDS $(\mathrm{r}=-0.47, \mathrm{p}=0.007)$. HRQoL benefits did not correlate with changes in other variables, including a reduction in dopaminergic therapy.

Following DBS, patients reduced dopaminergic therapy by an average of $499 \pm 881 \mathrm{LEU} \mathrm{mg} /$ day. There was no change in postoperative MMSE $(27.4 \pm 6.8$ at baseline, $26.7 \pm 7.6$ at assessment 2, and $28.5 \pm 1.7$ at assessment $3, \mathrm{p}=0.7$ ) or Geriatric Depression Scale scores $(5.1 \pm 2.9$ at baseline, $4.4 \pm 2.7$ at assessment 2, $5.1 \pm 3.3$ at assessment $3, \mathrm{p}=0.8$ ). No patient experienced

Table 1 Sociodemographic and clinical characteristics at baseline

\begin{tabular}{llc}
\hline Sex, male:female & & $11: 10$ \\
Age (years), mean \pm SD & & $61.5 \pm 8.6$ \\
Age (years) at onset, mean \pm SD & & $47.7 \pm 8.9$ \\
Level of education (years), mean \pm SD & & $13.8 \pm 2.6$ \\
Employment status & Employed (no) & 5 \\
& Retired (no) & 2 \\
& Disabled (no) & 14 \\
Marital status, number & Married (no) & 18 \\
& Divorced (no) & 2 \\
Family history of Parkinson's disease (no) & Single (no) & 1 \\
Levodopa equivalent units dosage, mean & & 4 \\
mg/day \pm SD* & & $1259 \pm 677$ \\
Patients on dopamine agonist (no) & & 17 \\
Hoehn and Yahr score, mean $\pm S D$ & On-state & $2.3 \pm 0.5$ \\
& Off-state & $3.2 \pm 0.6$
\end{tabular}

* Similar to prior studies, LEU was based on the following formula: regular levodopa dose + controlled-release levodopa $\times 0.75$ +levodopa $\times 0.25$ if on entacapone+ pramipexole $\times 67$

+ ropinirole $\times 16.7+$ apomorphine $\times 8$ (all dosages in milligrams). ${ }^{45}$ serious or persistent complications related to DBS, and none has required DBS revision.

\section{DISCUSSION}

The primary finding of our study was that various aspects of HRQoL improved following STN DBS, particularly satisfaction with motor function and independence. Improvements, however, did not extend to the OLS ${ }^{\mathrm{M}}$-A, which addresses general life issues, such as occupational function, interpersonal relationships, leisure activities and living conditions. Importantly, in our population, no $\mathrm{OLS}^{\mathrm{M}}$ domains significantly worsened following DBS. Overall, the results of this study are consistent with those that have utilised HS questionnaires, such as the PDQ-39. As we did not directly compare the OLS ${ }^{\mathrm{M}}$ with the PDQ-39, we cannot establish how these instruments might correlate or diverge in clinical practice. A recent cross-sectional survey of PD patients compared the PDQ-39 to the SEIQoL, a generic quality-of-life instrument which, like the $\mathrm{OLS}^{\mathrm{M}}$, allows each patient to factor in what elements he/she considers to be important at that time. ${ }^{13}$ The authors found that social, cognitive and emotional factors better predict overall quality of life compared with physical aspects of disease, but there was significant variability among individuals. As the PDQ-39 heavily emphasises motor function, the findings of that study question its relevance as a quality of life measure in PD. Our study cannot comment on which life areas are most important in PD patients at large, but it does demonstrate that patients undergoing DBS place high importance on the motor aspects of their disease and that many important health domains improve following surgery. The fact that other relevant life domains (eg, financial security) do not improve is incontrovertible but should not diminish the benefits which are obtained.

The present study was not focused on cognitive parameters and did not include postoperative psychometric testing apart from the MMSE, which is insensitive to the spectrum of cognitive deficits that have increasingly been associated with STN DBS. ${ }^{4-7}$ The study does, however, provide some insight regarding how patients perceive their cognitive status following DBS. Despite evidence that even subtle cognitive problems which follow STN stimulation may restrict patient function, ${ }^{30}$ we found a trend towards improved satisfaction regarding memory and clarity of thinking after DBS $(p=0.08)$. In contrast, there was a decline in satisfaction regarding articulation and fluency of speech which did not reach statistical significance $(0.71 \pm 8.5$ at baseline, $4.63 \pm 8.7$ at assessment 2 , and $-1.58 \pm 8.2$ at assessment $3, p=0.13$ ). This is consistent with our findings of declines in verbal fluency and recall in our patients following STN DBS despite good motor outcome. ${ }^{5}$ A prior study found that some PD patients suffer from a negative alteration of body image, loss of vitality, and both social and professional maladaption after DBS. ${ }^{9}$ The OLSM-DBS does not have content regarding alterations in self-perception, but satisfaction regarding stimulator side effects and conspicuousness (including the casing and scars) was high. Furthermore, the OLS $^{\mathrm{M}}-\mathrm{G}$ (general health module) showed a significant improvement in 'energy level/ enjoyment of life,' and no trend towards diminished 'inner peace' following DBS. It is unknown whether a formal psychological assessment would have found evidence of personal or interpersonal maladjustment following DBS, and further work is needed to better define how the neuropsychiatric and cognitive changes which follow STN DBS impact patient function and HRQoL.

We found a moderate association between HRQoL and improvements in the GDS. This finding is congruent with prior work which has shown that depression is an important 
Table 2 Clinical outcome following STN DBS

\begin{tabular}{|c|c|c|c|c|c|}
\hline \multicolumn{2}{|l|}{ Instrument } & \multirow{2}{*}{$\begin{array}{c}\begin{array}{l}\text { Assessment } 1 \\
\text { (baseline) }\end{array} \\
12.4 \pm 5.9\end{array}$} & \multirow{2}{*}{\begin{tabular}{|l}
$\begin{array}{l}\text { Assessment } 2 \\
\text { (7.4 }\end{array}$ \\
$3.7 \pm 4$ months) \\
\end{tabular}} & \multirow{2}{*}{$\begin{array}{c}\begin{array}{l}\text { Assessment } 3 \\
\text { (16.6 } \mathbf{6} .8 \text { months) }\end{array} \\
4.1 \pm 6.0 \\
\end{array}$} & \multirow{2}{*}{$\begin{array}{l}\begin{array}{l}\text { Significance } \\
\text { (p value) }\end{array} \\
<0.001\end{array}$} \\
\hline LFADLDS & & & & & \\
\hline \multirow[t]{3}{*}{ UPDRS } & Part I & $2.6 \pm 1.7$ & $1.8 \pm 1.4$ & $2.0 \pm 2.4$ & 0.25 \\
\hline & Part III off-state (on-state) & $36.9 \pm 19.4(27.3 \pm 16.4)$ & $25.1 \pm 11.9$ & $23.2 \pm 11.9$ & 0.03 \\
\hline & Part IV & $8.5 \pm 3.5$ & $3.6 \pm 3.6$ & $4.7 \pm 3.4$ & 0.004 \\
\hline \multicolumn{2}{|c|}{ EO-5D Preference-weighted Index Score } & $0.954 \pm 0.07$ & $0.983 \pm 0.05$ & $0.962 \pm 0.08$ & 0.3 \\
\hline \multirow{2}{*}{$\mathrm{OLS}^{\mathrm{M}}$ Summary Scores } & Movement disorders (MD) & $10.5 \pm 73.4$ & $89.1 \pm 54.0$ & $49.0 \pm 65.3$ & 0.007 \\
\hline & Deep brain stimulation (DBS) & not applicable & $59.9 \pm 19.0$ & $54.6 \pm 20.2$ & - \\
\hline
\end{tabular}

All results are listed as mean \pm SD. Scores for the $\mathrm{QLS}^{\mathrm{M}}-\mathrm{A}$ and $\mathrm{QLS}{ }^{\mathrm{M}}-\mathrm{G}$ modules may range between 96 and 160 ; scores for the $\mathrm{QLS}{ }^{\mathrm{M}}-\mathrm{MD}$ and $\mathrm{QLS}{ }^{\mathrm{M}}-\mathrm{DBS}$ modules may range from 144 to 240 and from 60 to 100 , respectively.

indicator of HS. ${ }^{12-1446} \mathrm{HRQoL}$ was also associated with UPDRS part II scores, a measure of activities of daily living, as might be expected based upon shared content between these measures. Among baseline characteristics, HRQoL correlated best with the reduction in Hoehn and Yahr score between the medically 'off' and 'on' states. Because the Hoehn and Yahr score is heavily influenced by balance, we hypothesise that postural instability influences movement disorder-related quality of life to a greater extent than other motor features, such as tremor. Worsening Hoehn and Yahr scores have previously been shown to negatively impact HS. ${ }^{14} 18$ Our work shows that among DBS candidates, those who have the most robust reduction in Hoehn and Yahr score with dopaminergic therapy are the most likely to experience better HRQoL following surgery. Additional studies are needed to better define which clinical variables best predict enhanced HRQoL following DBS, as such data will guide refinements in patient selection criteria.

We recognise limitations of this study including the small sample size and lack of a control population. To date, there have been few randomised controlled trials of DBS versus medical management, and both ethical and practical concerns preclude a double-blind, placebo-controlled study. ${ }^{29} 47$ Studies comparing surgical patients with those treated with optimal medical therapy have reported efficacy data favouring DBS, but the surgical patients generally experienced more severe adverse effects. ${ }^{3} 3148$ Since our study only included patients with bilateral STN DBS, it cannot address whether unilateral stimulation or an alternate target, such as the globus pallidus, would be preferable. ${ }^{3} 3049-51$ Like all questionnaires, the OLS ${ }^{M}$ has limitations. It has not yet been extensively studied in the PD population, so its test-retest reliability, sensitivity to change and the minimum clinically relevant change have not been established. Because the OLS ${ }^{\mathrm{M}}$ is designed to assess a range of movement disorders (including essential tremor and dystonia), it is less targeted to PD than currently available HS instruments, such as the PDQ39 and PDQL. For example, the OLS ${ }^{\mathrm{M}}$ does not include questions regarding sleep attacks (like the PDO39) or drooling (like the PDOL). However, OLS ${ }^{\mathrm{M}}$ does assess the core motor and non-motor features of PD including balance, dexterity, independence, fatigue, anxiety, pain and autonomic symptoms, and it is the only available movement disorder questionnaire to weight satisfaction in light of patient-rated importance. Our findings, therefore, extend the previously reported beneficial effects of STN DBS on various HS measures by demonstrating high personal satisfaction with DBS, particularly with respect to domains of the OLS ${ }^{\mathrm{M}}$ related to general health and disorders of movement.
Acknowledgements The study was supported by a grant from Medtronic, Inc.

Funding The study was supported by a grant from Medtronic, Inc. World Headquarters at 710 Medtronic Parkway, Minneapolis, MN 55432-5604, USA.

\section{Competing interests None.}

Ethics approval Ethics approval was provided by the Baylor College of Medicine, Houston, Texas.

Provenance and peer review Not commissioned; externally peer reviewed.

\section{REFERENCES}

1. Benabid AL, Chabardes S, Mitrofanis J, et al. Deep brain stimulation of the subthalamic nucleus for the treatment of Parkinson's disease. Lancet Neurol 2009;8:67-81.

2. Kenney C, Simpson R, Hunter C, et al. Short-term and long-term safety of deep brain stimulation in the treatment of movement disorders. J Neurosurg 2007;106:621-5.

3. Weaver FM, Follett K, Stern M, et al. CSP 468 Study Group. Bilateral deep brain stimulation vs best medical therapy for patients with advanced Parkinson disease: a randomized controlled trial. JAMA 2009;301:63-73.

4. Parsons TD, Rogers SA, Braaten AJ, et al. Cognitive sequelae of subthalamic nucleus deep brain stimulation in Parkinson's disease: a meta-analysis. Lancet Neurol 2006;5:578-88.

5. York MK, Dulay M, Macias A, et al. Cognitive declines following bilateral subthalamic nucleus deep brain stimulation for the treatment of Parkinson's disease. J Neurol Neurosurg Psychiatr 2008;79:789-95.

6. Alberts JL, Voelcker-Rehage C, Hallahan $\mathrm{K}$, et al. Bilateral subthalamic stimulation impairs cognitive-motor performance in Parkinson's disease patients. Brain 2008;131:3348-60.

7. Williams A, Arzola GM, Strutt AM, et al. A controlled study of the long-term cognitive outcome of bilateral subthalamic nucleus deep brain stimulation. Neurology 2009;72 (Suppl 3):A221.

8. Voon V, Krack P, Lang AE, et al. A multicentre study on suicide outcomes following subthalamic stimulation for Parkinson's disease. Brain 2008;131:2720-8.

9. Schüpbach M, Gargiulo M, Welter ML, et al. Neurosurgery in Parkinson disease: a distressed mind in a repaired body? Neurology 2006;66:1811-6.

10. Deuschl G, Herzog J, Kleiner-Fisman G, et al. Deep brain stimulation: postoperative issues. Mov Disord 2006;21(Suppl 14):S219-37.

11. Den Oudsten BL, Van Heck GL, De Vries J. Quality of life and related concepts in Parkinson's disease: a systematic review. Mov Disord 2007;22:1528-37.

12. The Global Parkinson's Disease Survey (GPDS) Steering Committee. Factors impacting on quality of life in Parkinson's disease: results from an international survey. Mov Disord 2002;17:60-7.

13. Lee MA, Walker RW, Hildreth AJ, et al. Individualized assessment of quality of life in idiopathic Parkinson's disease. Mov Disord 2006;21:1929-34.

14. Forsaa EB, Larsen JP, Wentzel-Larsen T, et al. Predictors and course of healthrelated quality of life in Parkinson's disease. Mov Disord 2008;23:1420-7.

15. Rahman S, Griffin HJ, Quinn NP, et al. Quality of life in Parkinson's disease: the relative importance of the symptoms. Mov Disord 2008:23:1428-34.

16. Den Oudsten BL, Van Heck GL, De Vries J. The suitability of patient-based measures in the field of Parkinson's disease: a systematic review. Mov Disord 2007:22:1390-401.

17. WHOQOL group. The World Health Organization Quality of Life assessment (WHOOOL) position paper from the World Health Organization. Soc Sci Med 1995:41:1403-9.

18. Schrag A, Jahanshahi M, Quinn N. What contributes to quality of life in patients with Parkinson's disease? J Neurol Neurosurg Psychiatr 2000;69:308-12.

19. Montel SR, Bungener C. Coping and quality of life of patients with Parkinson disease who have undergone deep brain stimulation of the subthalamic nucleus. Surg Neurol 2008. Published Online First: Sep 9. doi:10.1016/j.surneu.2008.05.026. 
20. Smith KW, Avis NE, Assmann SF. Distinguishing between quality of life and health status in quality of life research: a meta-analysis. Qual Life Res 1999;8:447-59.

21. Diamond A, Jankovic J. The effect of deep brain stimulation on quality of life in movement disorders. J Neurol Neurosurg Psychiatr 2005:76:1188-93.

22. Martinez-Martin P, Deuschl G. Effect of medical and surgical interventions on health-related quality of life in Parkinson's disease. Mov Disord 2007:22:757-65.

23. Lezcano E, Gomez-Esteban JC, Zarranz JJ, et al. Improvement in quality of life in patients with advanced Parkinson's disease following bilateral deep-brain stimulation in subthalamic nucleus. Eur J Neurol 2004:11:451-4.

24. Erola T, Karinen P, Heikkinen E, et al. Bilateral subthalamic nucleus stimulation improves health-related quality of life in Parkinsonian patients. Parkinsonism Relat Disord 2005;11:89-94.

25. Gronchi-Perrin A, Viollier S, Ghika J, et al. Does subthalamic nucleus deep brain stimulation really improve quality of life in Parkinson's disease? Mov Disord 2006:21:1465-8.

26. Siderowf A, Jaggi JL, Xie SX, et al. Long-term effects of bilateral subthalamic nucleus stimulation on health-related quality of life in advanced Parkinson's disease. Mov Disord 2006;21:746-53

27. Martínez-Martín P, Valldeoriola F, Tolosa E, et al. Bilateral subthalamic nucleus stimulation and quality of life in advanced Parkinson's disease. Mov Disord 2002;17:372-7.

28. Drapier S, Raoul S, Drapier D, et al. Only physical aspects of quality of life are significantly improved by bilateral subthalamic stimulation in Parkinson's disease. J Neurol 2005;252:583-8.

29. Deuschl G, Schade-Brittinger C, Krak P, et al. A randomized trial of deep-brain stimulation for Parkinson's disease. N Engl J Med 2006;355:896-908.

30. Zahodne LB, Okun MS, Foote KD, et al. Greater improvement in quality of life following unilateral deep brain stimulation surgery in the globus pallidus as compared to the subthalamic nucleus. J Neurol 2009. Published Online First: Apr 12 doi:10.1007/s00415-009-5121-7.

31. Just H, Ostergaard K. Health-related quality of life in patients with advanced Parkinson s disease treated with deep brain stimulation of the subthalamic nuclei. Mov Disord 2002;17:539-45.

32. Lagrange $\mathbf{E}$, Krack $P$, Moro $E$, et al. Bilateral subthalamic nucleus stimulation improves health-related quality of life in PD. Neurology 2002;59:1976-8.

33. Spottke EA, Volkmann J, Lorenz D, et al. Evaluation of healthcare utilization and health status of patients with Parkinson's disease treated with deep brain stimulation of the subthalamic nucleus. J Neurol 2002;249:759-66.

34. Kuehler A, Henrich G, Schroeder U, et al. A novel quality of life instrument for deep brain stimulation in movement disorders. J Neurol Neurosurg Psychiatr 2003; 74:1023-30

35. Hughes AJ, Daniel SE, Kilford L, et al. Accuracy of clinical diagnosis of idiopathic Parkinson's disease: a clinico-pathological study of 100 cases. J Neurol Neurosurg Psychiatr 1992;55:181-4.
36. Defer GL, Widner $\mathrm{H}$, Marie RM, et al. Core assessment program for surgical interventional therapies in Parkinson's disease (CAPSIT-PD). Mov Disord 1999:14:572-84

37. Krabbe PF, Weïnen T. Guidelines for analyzing and reporting EQ-5D outcomes. In: Brooks R, Rabin R, De Charro F, eds. The measurement and valuation of health status using EQ-5D: the European perspective. Dordrecht, The Netherlands: Kluwer Academic Publishers, 2003.

38. McHorney CA, Ware JE, Raczek AE. The MOS 36-item short-form health survey (SF-36): II. Psychometric and clinical tests of validity in measuring physical and menta health constructs. Med Care 1993;31:247-63.

39. Goldbeck L, Schmitz TG, Besier T, et al. Life satisfaction decreases during adolescence. Qual Life Res 2007:16:969-79.

40. Yesavage JA, Brink TL, Rose TL. Development and validation of a geriatric depression screening scale: a preliminary report. J Psychiatr Res 1983:17:37-49.

41. Fahn S, Elton RL. for the members of the UPDRS Development Committee. Unified Parkinson's Disease Rating Scale. In: Fahn S, Marsden CD, Calne DB, eds. Recent developments in Parkinson's disease. London, England: Macmillan Publishing Co Inc, 1987:153-63.

42. Parkinson Study Group. Evaluation of dyskinesias in a pilot, randomized, placebocontrolled trial of remacemide in advanced Parkinson disease. Arch Neurol 2001;58:1660-8

43. Hoehn MM, Yahr MD. Parkinsonism: onset, progression and mortality. Neurology 1967:17:427-42.

44. Folstein MF, Folstein SE, McHugh PR. 'Mini-mental state': a practical method for grading the cognitive state of patients for the clinician. J Psychiatr Res 1975:12:189-98.

45. Parkin SG, Gregory RP, Scott R, et al. Unilateral and bilateral pallidotomy for idiopathic Parkinson's disease: a case series of 115. Mov Disord 2002;17:682-92.

46. Tröster Al, Fields JA, Wilkinson S, et al. Effect of motor improvement on quality of life following subthalamic stimulation is mediated by changes in depressive symptomatology. Stereotact Funct Neurosurg 2003:80:43-7.

47. Witt K, Daniels C, Reiff J, et al. Neuropsychological and psychiatric changes after deep brain stimulation for Parkinson's disease: a randomised, multicentre study. Lancet Neurol 2008:7:605-14.

48. Valldeoriola F, Morsi 0, Tolosa E, et al. Prospective comparative study on costeffectiveness of subthalamic stimulation and best medical treatment in advanced Parkinson's disease. Mov Disord 2007;22:2183-91.

49. Esselink RA, De Bie RM, De Haan RJ, et al. Unilateral pallidotomy versus bilateral subthalamic nucleus stimulation in PD: a randomized trial. Neurology 2004:62:201-7.

50. Slowinski JL, Putzke JD, Uitti RJ, et al. Unilateral deep brain stimulation of the subthalamic nucleus for Parkinson disease. J Neurosurg 2007;106:626-32.

51. Volkmann J, Albanese A, Kulisevsky J, et al. Long-term effects of pallidal or subthalamic deep brain stimulation on quality of life in Parkinson's disease. Mov Disord 2009:24:1154-61. 